\title{
Cushing's disease presenting with avascular necrosis of the femoral heads and complicated by pituitary apoplexy
}

\author{
I P WICKS, ${ }^{1}$ D CALLIGEROS ${ }^{2}$ W KIDSON ${ }^{2}$ AND J V BERTOÜCH \\ From ${ }^{1}$ Prince Henry Hospital, Sydney, Australia and ${ }^{2}$ Prince of Wales Hospital, Sydney, Australia
}

SUMmARY A case of Cushing's disease presenting with avascular necrosis of the femoral heads is described. Eighteen months after the onset of hip symptoms the patient developed pituitary apoplexy and presented to hospital as a medical emergency. Endogenous hypercortisolism is a rare and important cause of avascular necrosis of bone.

Key words: pituitary neoplasms, hypercorticism, osteonecrosis.

\section{Case report}

An obese 39 year old man developed progressive hip pain and stiffness over an 18 month period. Nonsteroidal anti-inflammatory agents failed to control his symptoms. A diagnosis of osteoarthritis of the hips was made and bilateral hip replacements recommended.

Shortly before joint replacement surgery was planned the patient presented to hospital with severe bifrontal headache associated with blurring of vision, diplopia, vomiting, polyuria, and polydipsia. When questioned, the patient said he had always exceeded his ideal body weight but in the last five years this had increased to $110 \mathrm{~kg}$. There were no other symptoms of endocrine or musculoskeletal dysfunction. He consumed approximately 60 grams of alcohol each day.

Physical examination showed centripetal obesity, a buffalo hump, moon facies, generalised pigmentation, and gynaecomastia (Fig. 1). There were 3rd, 4th, ophthalmic division of 5th and 6th cranial nerve palsies on the right side. Bitemporal hemianopia was also present. The blood pressure was $115 / 70$

Accepted for publication 1 May 1987.

Correspondence to Dr J V Bertouch, Department of Rheumatology, Prince Henry Hospital, Anzac Parade, Little Bay, NSW 2036. Australia.
$\mathrm{mmHg}$ and there was variable bradycardia (pulse rate $28-44 / \mathrm{min}$ ).

An urgent computed tomographic (CT) brain scan showed a large mass in the pituitary fossa which extended into the interpeduncular cistern (Fig. 2). A blood count showed neutrophil leucocytosis and lymphopenia (white cell count $23.9 \times 10^{9} / 1$; neutrophils $90 \%$, lymphocytes $6 \%$ ). Serum electrolytes were normal. A random blood glucose was 8.9 $\mathrm{mmol} / \mathrm{l}$ (normal 3.5-5.5). Osmolalities confirmed diabetes insipidus (urine $157 \mathrm{mmol} / \mathrm{kg}$; serum 304 $\mathrm{mmol} / \mathrm{kg}$ ). The results of serum endocrine investigations were as follows: thyroxine $66 \mathrm{nmol} / \mathrm{l}$ (normal 80-150), tri-iodothyronine $0.4 \mathrm{nmol} / 1$ (normal 1.4 $2 \cdot 8$ ), thyroid stimulating hormone $0 \cdot 1$ arb. unit (AU) (normal 0-5), luteinising hormone 1.9 AU (normal 2-9), follicle stimulating hormone 3.6 AU (normal 2-5), testosterone $1.93 \mathrm{nmol} / \mathrm{l}$ (normal 8.4-34), prolactin $0.08 \mathrm{nmol} / \mathrm{l}$ (normal $0 \cdot 08-0 \cdot 38$ ), growth hormone undetectable, cortisol at $7.00 \mathrm{pm}$ $2164 \mathrm{nmol} / \mathrm{l}$ (normal 155-599), adrenocorticotrophic hormone (ACTH) $33 \mathrm{pmol} / 1$ (normal<11).

A diagnosis of Cushing's disease with pituitary apoplexy was made and urgent craniotomy arranged. At operation a large pituitary tumour measuring $3 \mathrm{~cm} \times 2 \mathrm{~cm} \times 2 \mathrm{~cm}$ was found. There was extensive necrosis of pituitary tissue. The tumour was excised, apart from a small remnant attached to the right internal carotid artery. Histological ex- 


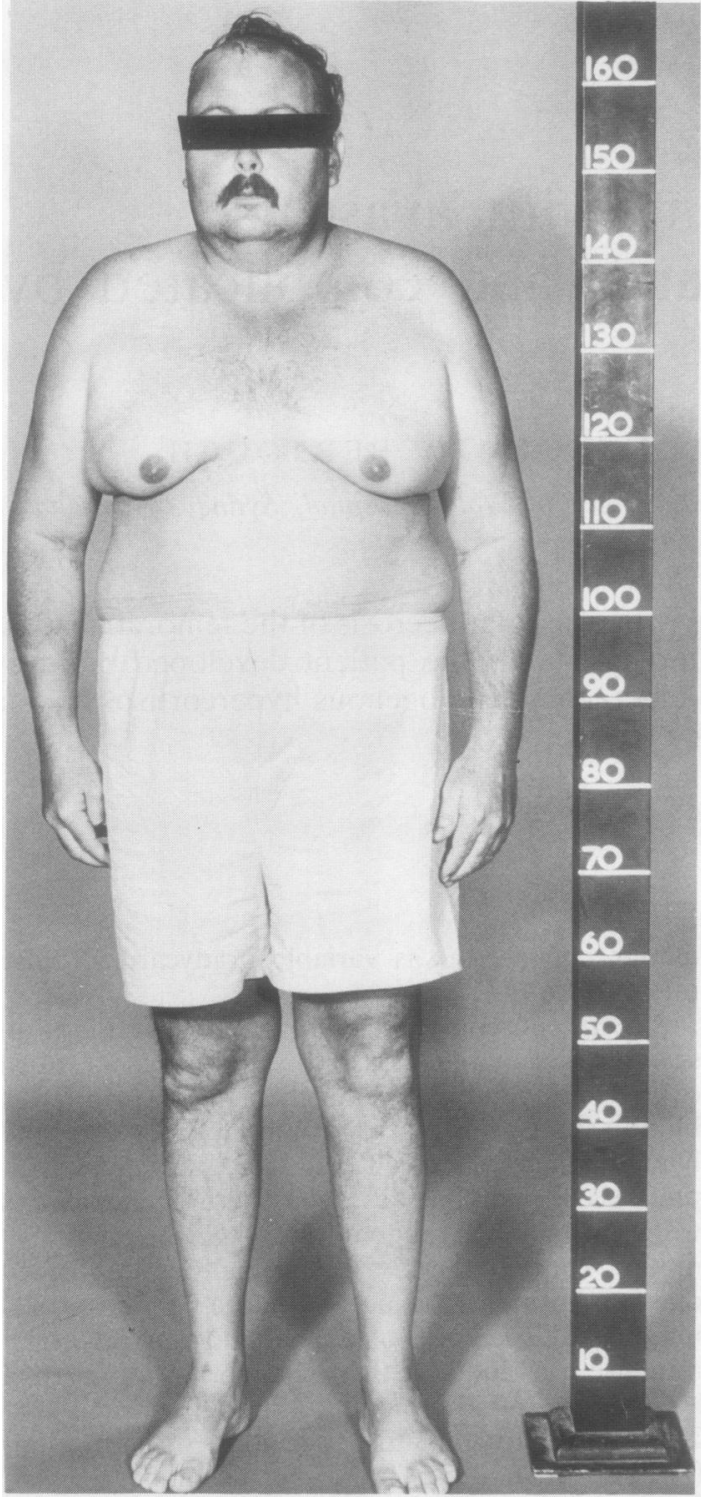

Fig. 1 A photograph of the patient showing centripetal obesity, moon facies, and gynaecomastia.

amination showed an acidophilic pituitary tumour which had invaded the surrounding capsule. Immunocytochemistry confirmed that the tumour produced ACTH.

After surgery visual acuity was $6 / 18$ in the right eye and $1.5 / 60$ in the left eye. Right sided 3rd, 4th, and 6th cranial nerve palsies were still present. Treatment was started with replacement hormone therapy and the patient underwent a course of

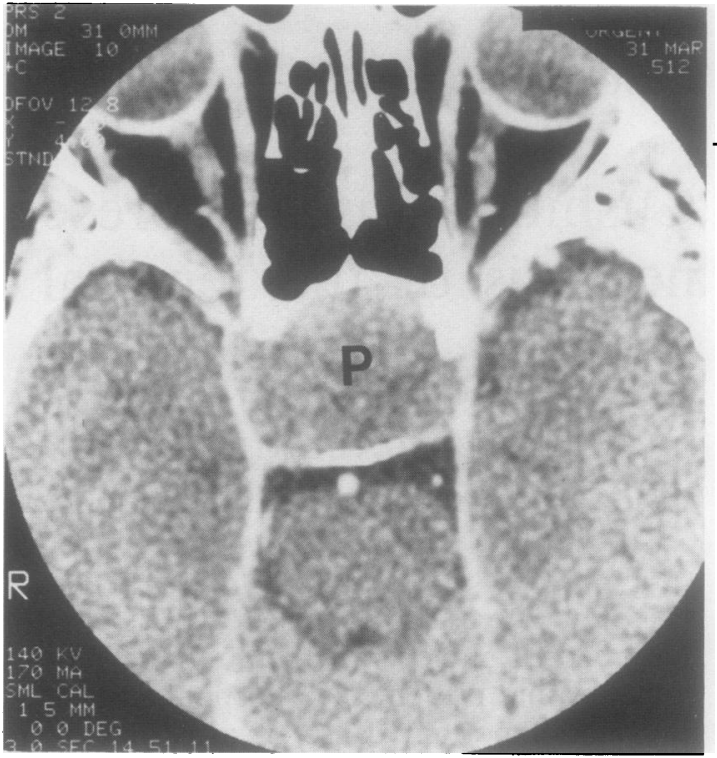

Fig. 2 Computed tomographic brain scan showing a large pituitary tumour $(P)$ expanding the pituitary fossa.

radiotherapy (50 Gy over five weeks). Repee investigations four months after surgery showed thal serum cortisol at $7.00 \mathrm{pm}$ had fallen to $514 \mathrm{nmol} / \mathrm{l}$ (normal 155-599) and serum ACTH to $12 \cdot 1 \mathrm{pmol} / \mathrm{l}$ (normal <11).

Postoperatively the patient's hip pain was dramatically improved. Stiffness continued, however, and examination showed severe generalised restriction of both hips. Review of the original $x$ rays showed avascular necrosis of the femoral heads (Fig. 3). This was confirmed by bone scan.

\section{Discussion}

A pituitary adenoma is the most common cause of non-iatrogenic Cushing's syndrome. The tumour is usually a microadenoma less than $10 \mathrm{~mm}$ in diameter, and fewer than $10 \%$ produce pituitary enlargement. ${ }^{1}$ Cushing's disease is nine times more common in women than in men. ${ }^{2}$

Avascular necrosis of bone (ANB) is a well $N$ described complication of treatment with corticosteroids. It may even occur with physiological doses of $\omega$ corticosteroids administered as replacement therapy in hypopituitarism and Addison's disease. ${ }^{3}$ ANB was not mentioned, however, in a recent view of the $\mathbb{D}$ early manifestations of Cushing's syndrome. ${ }^{4}$ The pathogenesis of steroid related ANB is uncertain. In $\frac{7}{0}$ animal studies corticosteroid administration has $\underset{\mathbb{D}}{\vec{D}}$ been shown to cause fatty liver, hyperlipidaemia, 


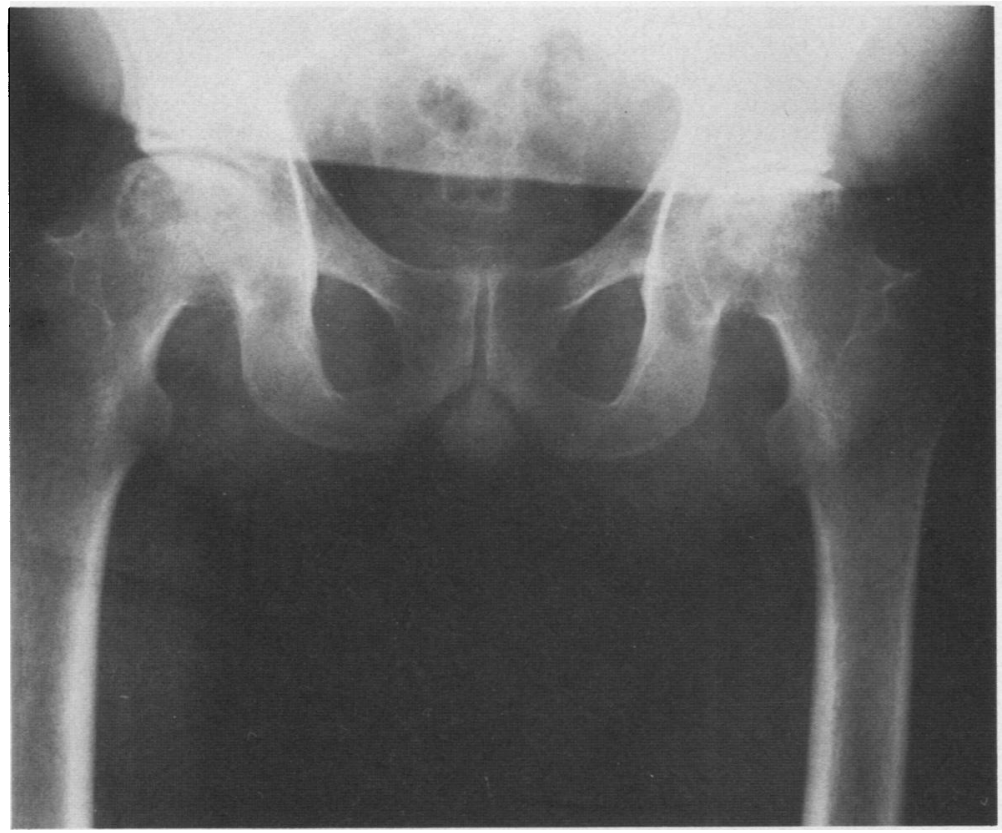

Fig. 3 An $x$ ray of the pelvis showing lucent and sclerotic regions within flattened femoral heads and some loss of articular cartilage. Changes on the left are partly obscured by the patient's fatty apron.

and fat embolisation to subchondral arterioles. In addition, bone marrow fat cell volume of the femoral heads increased by 25 to $28 \% .^{5}$ Fatty liver has been described in Cushing's syndrome, ${ }^{6}$ and it has been suggested that fat embolisation from this source may be responsible for steroid related ANB. ${ }^{7}$ In another study abnormal intraosseous venograms and increase of femoral head bone marrow presures were found in a group of patients with systemic lupus erythematosus and ANB who were taking corticosteroids. ${ }^{8}$ Vascular perfusion of the femoral head might therefore be impaired by hypertrophy of intramedullary lipocytes. 58

Excess alcohol intake has also been associated with ANB. ${ }^{9}$ It had been postulated that this association is due to fat embolism. ${ }^{10}$ Although our patient's intake was moderate, there were no clinical features of liver diseases, and liver function tests (including $\gamma$-glutamyltransferase) were normal.

ANB complicating endogenous hypercortisolism is rare. Although several authors briefly mention the association, ${ }^{11-13}$ there are only three well documented cases in the literature..$^{14-16}$ Hypercortisolism was secondary to bilateral adrenal hyperplasia in two patients and to an adrenal adenoma in one patient. ANB occurred in the femoral and humeral heads.

Perhaps more importantly, ANB may be the presenting manifestation of endogenous hypercortisolism. This has been described in two cases. ${ }^{15} 16$
One patient presented with avascular necrosis of the femoral heads and also had multiple symptoms of hypercortisolism. ${ }^{15}$ The case described by Sharon et al presented with avascular necrosis of the femoral head and labile hypertension. ${ }^{16}$

Our patient presented with avascular necrosis of the femoral heads and weight gain. Cushing's disease was not recognised, and the patient subsequently became a medical emergency when pituitary apoplexy occurred. After excision of the pituitary tumour there was dramatic relief of hip pain. At follow up after six months this improvement was sustained, and the patient complained only of hip stiffness. It is tempting to attribute the reduction in hip pain to treatment of the hypercortisolism and reversal of its metabolic consequences. This case shows that ANB may be the presenting manifestation of Cushing's disease, and that hypercortisolism should be excluded in all patients with 'idiopathic' ANB.

Figures 1-3 were produced by the Department of Medical Illustration. University of New South Wales and teaching hospitals.

\section{References}

1 Krieger D T. Pathophysiology of Cushing's disease. Endocr Rev 1983; 4: 22-43.

2 Wilson J D, Foster D W, eds. William's textbook of endocrinology. 6th ed. Philadelphia: Saunders, 1982. 
3 Williams P L, Corbett M. Avascular necrosis of bone complicating corticosteroid replacement therapy. Ann Rheum Dis 1983 42: $276-9$.

4 Ross E J, Linch D C. Cushing's syndrome-killing discase: discriminatory value of signs and symptoms aiding carly diagnosis. Lancet 1982; ii: 646-9.

5 Wang G J, Sweet D E, Reger S I. Thompson R C. Fat-cell changes as a mechanism of avascular necrosis of the femoral head in cortisone-treated rabbits. J Bone Joint Surg /Am/ 1977: 59: $729-35$.

6 Soffa L J, Iannaccone A, Gabrilove J L. Cushing's syndrome: a study of fifty patients. Am J Med 1961; 30: 129-46.

7 Fisher D E. The role of fat embolism in the etiology of corticosteroid-induced avascular necrosis: clinical and experimental results. Clin Orthop 1978; 130: 68-80.

8 Zizic T M. Hungerford D S. Stevens M B. Ischemic bone necrosis in systemic lupus erythematosus. The early diagnosis of ischemic necrosis of bone. Medicine (Baltimore) 1980; 59: $134-42$.

9 Hungerford D S. Zizic T M. Alcoholism associated ischemic necrosis of the femoral head. Clin Orthop 1978; 130: 144-53.
10 Jones J P. Alcoholism, hypercortisonism, fat embolism and osseous avascular necrosis. In: Zinn W M. ed. Idiopathic ischemic necrosis of the femoral head in adults. Stuttgart: Thieme, 1971.

11 Frost H M, Villanueva A R. Roth H. McFarland P H. Human $\stackrel{\vec{D}}{\vec{D}}$ osteoblastic activity - the effect of cortisone on lamellar osteoblastic activity. Henry Ford Hosp Med Bull 1961: 9: 97-9.

12 Patterson R J, Bickel W H, Dahlin D C. Idiopathic avascular necrosis of the head of the femur. J Bone Joint Surg [Am] 1964; 46: $267-82$.

13 Fisher D E. Bickel W H. Corticosteroid-induced avascular necrosis: a clinical study of seventy-seven patients. J Bone Joint Surg [Am] 1971: 53: 859-73.

14 Madell S H. Freeman L M. Avascular necrosis of bone in Cushing's syndrome. Radiology 1964: 83: 1068-70.

15 Cerletty J M. Ziebert A P. Mueller K H. Avascular necrosis of the femoral head as the presenting manifestation of Cushing's disease. Clin Orthop 1973; 97: 69-73.

16 Sharon P, Kaplinsky N. Leiba S. Frankl O. Aseptic necrosis of head of femur: presenting manifestation in Cushing's disease. J Rheumatol 1977; 4: 73-5. 